\title{
Perfil funcional de usuários de serviços públicos e privados de reabilitação: proposta de indicadores para avaliar intervenções - estudo piloto
}

Amanda Neves Cruz Coelho, Fabiane Ribeiro Ferreira, Anderson Aurélio da Silva, Rosana Ferreira Sampaio

\begin{abstract}
Resumo
Três fatores estão relacionados com um bom processo de reabilitação: considerar todos os aspectos da vida da pessoa, reconhecer o indivíduo como o foco central na tomada de decisões e assegurar intervenções especificas para atender de forma efetiva suas demandas em todos os serviços de saúde. Testar indicadores para coleta de informações funcionais que permitam monitorar e avaliar o impacto de intervenções realizadas em serviços de reabilitação, na Atividade e Participação de usuários abordados nesses serviços. Trata-se de um estudo transversal, em fase piloto, cujos dados de 197 usuários foram coletados no período de 2015 a 2016 em serviços de reabilitação de Belo Horizonte. Foram realizadas entrevistas face a face, na semana de início do tratamento, utilizandose dois instrumentos de avaliação funcional cuja abordagem está ancorada na Classificação Internacional de Funcionalidade, Incapacidade e Saúde (CIF). O primeiro, o Escore de Limitação de Atividade (ELA), descreve 18 ações básicas da vida diária, em quatro domínios: experiências sensoriais, aprendizado básico e aplicação de conhecimento, comunicação e mobilidade. Já o Escore de Restrição de Participação (ERP) descreve 22 atividades complexas em cinco domínios: cuidado pessoal, vida doméstica, relações e interações interpessoais, áreas principais da vida e vida comunitária, social e cívica. Estas escalas foram criadas em 2010 por Mont \& Loeb que adotaram a quarta opção de operacionalização para atividade e participação propostas pela OMS. O ELA e o ERP têm uma escala de 0 a 100, com pesos por domínios, de forma a equalizar a importância dos mesmos no escore final. Do total de 197 usuários que deram entrada em serviços públicos e privados de reabilitação no período estudado, 66\% eram mulheres, a média de idade 51 anos e, aproximadamente, metade da amostra tinha cursado ensino fundamental (completo ou incompleto). Quanto ao estado civil, 46,8\% eram casados ou relataram união estável. O escore médio do ELA foi de 19,3 (Máx. 71,9; Min. 0), e para o ERP de 13,6 (Máx. 81,7; Min.0). O domínio da avaliação de atividade (ELA) que apresentou maior frequência de dificuldade severa foi Mobilidade sendo os piores itens avaliados "manter a posição do corpo", seguido por "mudar a posição do corpo" e "levantar, carregar, mover e manusear objetos". Na escala de participação (ERP), os domínios que apresentaram maior frequência de dificuldade severa foram: Vida Doméstica e Cuidado Pessoal, sendo os itens "realizar tarefas domésticas" e " vestir-se e despir-se", os mais citados respectivamente. A qualidade da assistência em saúde tem sido associada com a diminuição de custos, onde a abordagem assertiva inicial do usuário, sem necessidade de repetição de intervenções, é menos onerosa para os mesmos e para o sistema de saúde. Os escores apresentados pelos participantes deste estudo mostraram comprometimento importante no desempenho de funções básicas e dificuldades em lidar com atividades complexas no início do tratamento. Nesta pesquisa, os dois instrumentos deverão ser aplicados no momento da alta, para que se possa avaliar o impacto das intervenções de reabilitação na vida destas pessoas.
\end{abstract}

Descritores: Perfil funcional; Usuários; Serviços Públicos. 